\title{
Coking and deactivation behavior of Ba-La-modified alumina in the aldol condensation of methyl acetate with formaldehyde: effect of the \\ reactants composition
}

Qiang Bao ${ }^{1, *}$, Yunfeng $\mathrm{Hu}^{1}$, Xiaofei $\mathrm{Liu}^{2}$, Guoliang $\mathrm{Wu}^{1}$, Penglai Sun ${ }^{1}$, Junping $\mathrm{Ge}^{1}$, Ming $\mathrm{Xu}^{1}$

${ }^{1}$ Department of Chemistry \& Chemical Engineering, Northeast Petroleum

University, Daqing 163318, Heilongjiang, China

${ }^{2}$ Key Laboratory of Surface and Interface Chemistry of Jilin Province, College of Chemistry, Jilin University, Qianjin Road 2699, Changchun, 130012, PR China

\section{Corresponding Author}

Qiang Bao

Department of Chemistry \& Chemical Engineering, Northeast Petroleum University, Daqing, 163318, China

Tel/Fax: (+86) 0459-6503731

Email: baoqiang@nepu.edu.cn

\section{Supporting information}

The amount of catalyst was $500 \mathrm{mg}$ and it was doped with the quartz sands to a total constant volume of $3 \mathrm{ml}$. The products were identified and analyzed online by gas chromatography (GC-8A, FID) on a $60 \mathrm{~m}$ capillary column DB-WAX. Reaction device figure has been placed in the supporting information.

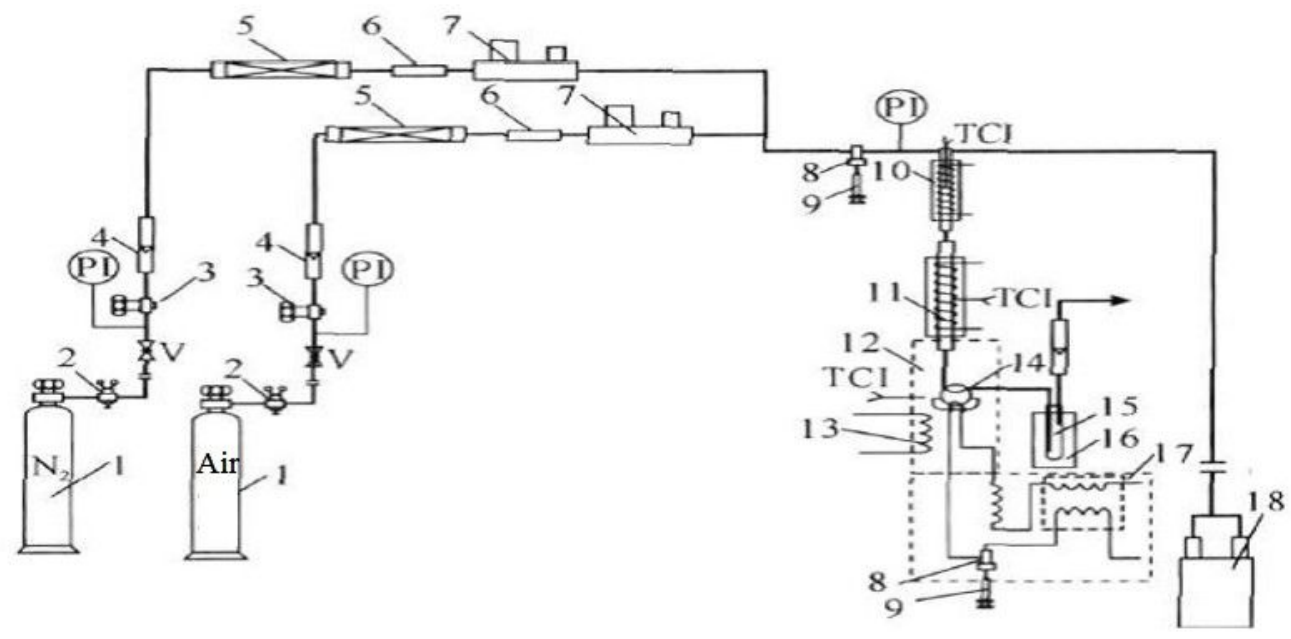

Figure S1. Reaction device figure 
TCl-temperature control sensor

$\mathrm{V}$-valve

PI-pressure gage

1-gas cylinder

2-relief valve

3-control valve

4-rotameter

5-dryer

6-air filter

7-mass flowmeter

8-sampler

9-injector

10-preheater

11-reactor

12-valve box

13-heating element

14-six-way valve

15-drip catcher

16-Cold hydrazine

17-chromatographic system

18-liquid feed pump

Compared with the fresh catalyst, the pore structure parameters of the regenerated catalyst did not change significantly, indicating that the pore structure of the regenerated catalyst restored well.

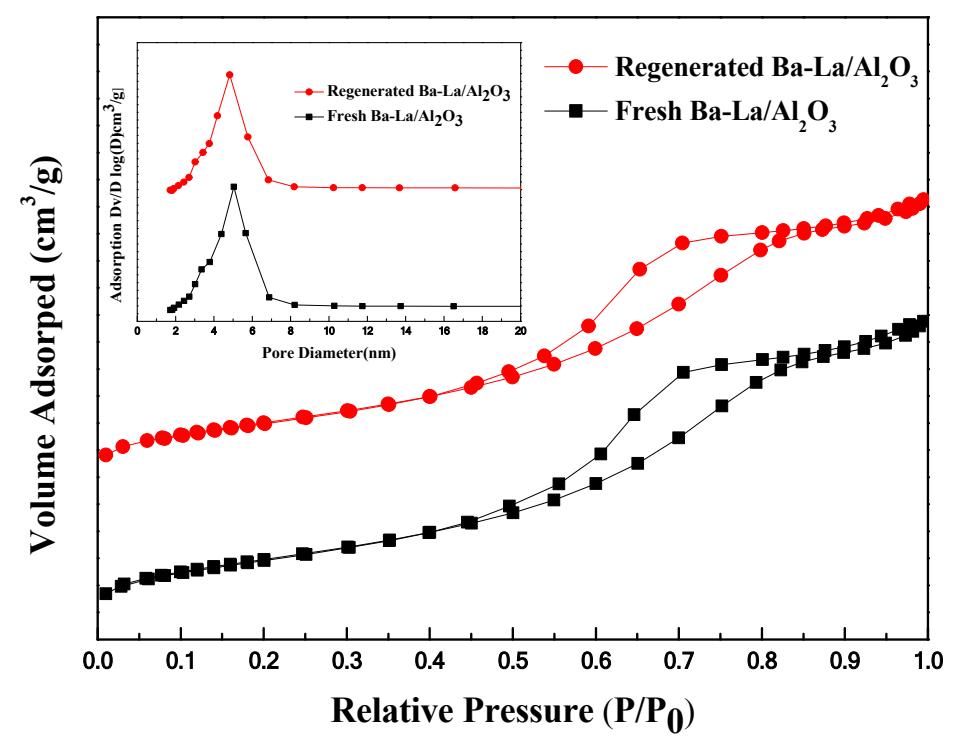

Figure S2. $\mathrm{N}_{2}$ adsorption and desorption isotherms of fresh and regenerated catalysts. 
Table S1. Textural properties of fresh and regenerated catalysts.

\begin{tabular}{lccc}
\hline Catalysts & $\mathrm{S}_{\mathrm{BET}}\left(\mathrm{m}^{2} / \mathrm{g}\right)$ & Mesoporous volume (cc/g) & Mesoporous diameter $(\mathrm{nm})$ \\
\hline $\mathrm{Ba}-\mathrm{La} / \mathrm{Al}_{2} \mathrm{O}_{3(\text { Fresh })}$ & 231.2 & 0.39 & 6.5 \\
$\mathrm{Ba}-\mathrm{La} / \mathrm{Al}_{2} \mathrm{O}_{3 \text { (Regenerated) }}$ & 220.9 & 0.37 & 6.4 \\
\hline
\end{tabular}

